\title{
Scenario of Tuberculosis in India
}

Tuberculosis (TB) is one of the most ancient diseases of mankind. Molecular evidence reveals it to be over 17,000 years old. WHO declared TB as a 'global public health emergency' in 1993. ${ }^{1,2}$ India is the highest TB burden country with an estimated incidence of 26.9 lakh cases in 2019 (WHO). India accounts for about $24 \%$ of the global prevalence, $23 \%$ of the global incident cases, and $21 \%$ of the global TB deaths Also, India has the largest number of individuals suffering from drug-resistant versions of the TB, like Multi-Drug Resistant Tuberculosis (MDR TB), Extensively Drug-Resistant Tuberculosis (XDR TB), and the Totally Drug-Resistant Tuberculosis (TDR TB). Paediatric and drug-resistant TB along with HIV leading to TB cases flare up and now in Corona virus Pandemic reduced immunity in TB patents leading to life threatening morbidity.

Paediatric TB has been relatively neglected as different pathophysiology from adults makes diagnosis challenging, and the lower priority traditionally afforded to children by TB control programmes. Research and surveillance data in the field of childhood TB are scarce. Children are at a much higher risk of severe disease and death than adults. Overall the risk of disease is reported highest among neonates, infants and then in late teens. 5 and 10 years age group ("safe school years") escape infection. Disease in young children, 15 to 30 years reflects new infection (incidence), rather than secondary reactivation and continuing transmission. The paediatric disease burden is a potential indicator of current transmission within a community with multi drug resistant (MDR), and extensively drug resistant (XDR) strains. Untreated Latent TB infections are root cause of future Epidemics.

Recent WHO guidance recommends reporting of all cases of childhood TB (smear positive, smear negative and extra pulmonary) in two age bands (0-4 and 5-14 years). TB in children remains an essential silent indicator of the effectiveness of National TB control programmes.

TB in Pregnant females is a special entity requiring attention .It leads to Obstetric complications like small for date uterus, spontaneous abortions, preterm labour, low birth weight, and increased neonatal mortality. High perinatal mortality reported in rare Congenital TB cases.

HIV and TB together make a deadly combo. Latent TB cases turns into frank symptomatic TB cases with added HIV infection. The number of HIV-infected people developing Tuberculosis is increasing in India, according to the India TB Report 2019, which was released by the government on September 25, 2019. The figures for India are depressing. HIV burden in India is third highest in the world with an adult prevalence of 0.22 per cent. The co-morbidities of TB do come mostly with HIV, but diabetes, and tobacco-related ailments are culprits too.

India ranks second in the world as far as TB-related mortality is concerned. About nine per cent of the global burden of HIVassociated TB is borne by India. Every year, 11,000 Indians die of HIV-associated TB. ${ }^{3}$

Drug resistant tuberculosis poses a big hurdle too. India has 26,966 MDR-TB patients, the highest in the world, while there are 2,130 XDR-TB patients in the country.
Volume 8 Issue 2 - 202 I

\author{
Jyoti Priyadarshini Shrivastava, ' Alok \\ Shrivastava ${ }^{2}$ \\ 'Department of Pathology, Gajra Raja Medical College, India \\ ${ }^{2}$ Department of Orthopedics, Madhya Pradesh Health and family \\ welfare department, Madhya Pradesh Medical University, India
}

Correspondence: Jyoti Priyadarshini Shrivastava, Associate
Professor, Department of Pathology, Gajra Raja Medical college,
Gwalior, India,Tel 9425029163, Email drpriyajyoti22@gmail.com

Received: December 24, 2020 | Published: April 01, 2021

According to the India TB Report 2019, the success rate of treatment of drug resistant TB patients has remained stagnant at 47 per cent, the same as in last year's report. However, the government says it is doing its best to provide optimum care to drug resistant TB patients. In addition to pulmonary MDR/RR TB patients, extra pulmonary diseases like lymph node TB \& pleural TB are also eligible for Shorter MDR TB regimen.

The notification of TB cases is a challenge because of their being poorly reported to government data from the private sector, and therefore the notification going up is being touted as an achievement in the 2019 report. The India TB report claims that the notification of TB cases has gone up by 16 per cent(2019) and 22\% (2020) . NIKSHAY Portal aims at $100 \%$ online notification. ${ }^{4-7}$

Global TB report $(2019)^{8}$ reveals that countries are making progress. About 7 million people were reported to have been reached with quality TB care in 2018, up from 6.4 million in 2017. In addition, TB-related deaths dropped from 1.6 million in 2017 to 1.5 million in 2018. However, TB remains the top infectious killer worldwide, with about 10 million people falling ill with TB in 2018 .

World Tuberculosis Day is celebrated on 24th March annually to increase efforts to end the global tuberculosis epidemic and to raise public awareness about the health, social and economic consequences of tuberculosis. Dr. Robert Koch in 1882 discovered the TB bacterium on this date .On this World TB Day, WHO calls on governments, affected communities, civil society organizations, health-care providers, NGO's and national/international partners to join hands under the banner "Find - Treat All. "End TB" to ensure everyone is covered. Revised National Tuberculosis Control Programme (RNTCP) is a programme for prevention and control of TB in India by Ministry of Health and Family Welfare, Government of India. It has integrated four strategic pillars of "Detect - Treat - Prevent - Build" (DTPB) under National Strategic Plan 2017-2025 for achieving the goal of TB elimination by 2025 .

As per TB Report 2020, The Control programme is now more patient Centric. TB Forums have been constituted in all states with over 700 (99\%) TB Forums formed in districts across the country. 'Tuberculosis Survivors to TB Champions' is an important strategy in engaging with TB affected communities. 
In 2020, after completion of 3 years of mission to End TB (2017-2025) the programme is renamed as "National Tuberculosis Elimination Program (NTEP)" from Revised National Tuberculosis Control Program (RNTCP). The theme for 2021 is 'The Clock is Ticking'.

The Tuberculosis menace is undergoing a setback presently due to COVID-19 pandemic leading to End TB progress at halt. India accounts for $26 \%$ of TB cases globally, the TB notifications during the period January-June 2020 fell by $25 \%$.

Despite significant progress over the last decades, TB is one of the top 10 causes of death worldwide. 7 million people receive record levels of lifesaving TB treatment but 3 million still miss out.

Knowledge and data are powerful weapons in the fight against tuberculosis. The WHO global TB report delivers a clear message that dedicated, sustained acceleration of efforts, fully funded, and increased collaboration are urgently required to turn the tide of the TB epidemic.We need to ensure ongoing prevention and care as per WHO's mission of achieving Universal Health Coverage. ${ }^{9-12}$

\section{References}

1. Gursimrat K Sandhu. Tuberculosis: current situation, challenges and overview of its control programs in India. $J$ Glob Infect Dis. 2011;3(2):143-150
2. Tuberculosis in India - Wikipedia

3. HIV-associated tuberculosis on the rise: India TB Report.

4. Central TB Division.

5. Hoskyns W. Paediatric tuberculosis. Postgraduate Medical Journal. 2003;79:272-278.

6. Newton SM, Brent AJ, Anderson S, et al. Paediatric tuberculosis. Lancet Infect Dis. 2008;8(8):498-510.

7. Walls T, Shingadia D. Global epidemiology of paediatric tuberculosis. $J$ Infect. 2004;48(1):13-22.

8. Siddharthya R, Sayan G. Tuberculosis: India's silent epidemic. The Diplomat; 2019.

9. Soumya S, Narendran G. HIV and tuberculosis in India. J Biosci. 2008;33(4):527-537.

10. Central TB division. Revised National TB control programme. Annual Report; 2020.

11. Sakshi S, Sandeep K. Tuberculosis in India: Road to elimination. Int $J$ Prev Med. 2019;10:114.

12. World Health Organization. Tuberculosis control in the South East Asia region. Annual TB Report. World Health Organization; 2015. 